\title{
Risk of regional recurrence in triple-negative breast cancer patients: a Dutch cohort study
}

\author{
Lori M. van Roozendaal ${ }^{1,8}{ }_{(\mathbb{C}} \cdot$ Leonie H. M. Smit $^{1,8} \cdot$ Gaston H. N. M. Duijsens $^{1}$ • \\ Bart de Vries $^{3,8}$ - Sabine Siesling ${ }^{4,5} \cdot$ Marc B. I. Lobbes $^{6} \cdot$ Maaike de Boer $^{7,8}$. \\ Johannes H. W. de Wilt ${ }^{2} \cdot$ Marjolein L. Smidt ${ }^{1,8}$
}

Received: 7 March 2016/Accepted: 14 March 2016/Published online: 25 March 2016

(c) The Author(s) 2016. This article is published with open access at Springerlink.com

\begin{abstract}
Triple-negative breast cancer is associated with early recurrence and low survival rates. Several trials investigate the safety of a more conservative approach of axillary treatment in clinically $\mathrm{T} 1-2 \mathrm{~N} 0$ breast cancer. Triple-negative breast cancer comprises only $15 \%$ of newly diagnosed breast cancers, which might result in insufficient power for representative results for this subgroup. We aimed to provide a nationwide overview on the occurrence of (regional) recurrences in triple-negative breast cancer patients with a clinically T1-2N0 status. For this cohort study, 2548 women diagnosed between 2005 and 2008 with clinically T1-2N0 triple-negative breast cancer were
\end{abstract}

Lori M. van Roozendaal

lorivanroozendaal@gmail.com

1 Department of Surgical Oncology, Maastricht University Medical Center, P.O. Box 5800, 6202 AZ Maastricht, The Netherlands

2 Department of Surgical Oncology, Radboud University Medical Center, Nijmegen, The Netherlands

3 Department of Pathology, Maastricht University Medical Center, Maastricht, The Netherlands

4 Department of Registration and Research, Comprehensive Cancer Organisation the Netherlands, Utrecht, The Netherlands

5 Department of Health Technology and Services Research, MIRA Institute for Technical Medicine and Biomedical Technology, University of Twente, Twente, The Netherlands

6 Department of Radiology and Nuclear Medicine, Maastricht University Medical Center, Maastricht, The Netherlands

7 Devision of Medical Oncology, Maastricht University Medical Center, Maastricht, The Netherlands

8 GROW - School for Oncology and Developmental Biology, Maastricht University Medical Center, Maastricht, The Netherlands selected from the Netherlands Cancer Registry. Follow-up data until 2014 were analyzed using Kaplan-Meier. Sentinel lymph node biopsy was performed in 2486 patients, and (completion) axillary lymph node dissection in 562 patients. Final pathologic nodal status was pN0 in $78.5 \%$, $\mathrm{pN} 1 \mathrm{mi}$ in $4.5 \%$, pN1 in $12.3 \%$, pN2-3 in $3.6 \%$, and $\mathrm{pNx}$ in $1.1 \%$. During a follow-up of 5 years, regional recurrence occurred in $2.9 \%$, local recurrence in $4.2 \%$ and distant recurrence in $12.2 \%$. Five-year disease-free survival was $78.7 \%$, distant disease-free survival $80.5 \%$, and 5-year overall survival $82.3 \%$. Triple-negative clinically T1-2N0 breast cancer patients rarely develop a regional recurrence. Their disease-free survival is more threatened by distant recurrence, affecting their overall survival. Consequently, it seems justified to include triple-negative breast cancer patients in randomized controlled trials investigating the safety of minimizing axillary staging and treatment.

Keywords Breast neoplasms - Triple-negative breast cancer · Follow-up · Recurrence $\cdot$ Sentinel lymph node biopsy $\cdot$ Axillary lymph node dissection

\section{Introduction}

Breast cancer knows a large heterogeneity of tumors characterized by several molecular profiles with different clinical behaviors and responses to therapy. In clinical practice, breast cancer patients are generally classified by clinical and histological tumor characteristics, axillary lymph node status, hormonal receptor status, and human epidermal growth factor receptor 2 (HER2) status [1-3]. Based on receptor status, several breast cancer subtypes are classified. One of these subtypes is triple-negative breast cancer (TNBC), which is characterized by the absence of (over)expression of 
estrogen receptor (ER), progesterone receptor (PR), and HER 2 receptor. TNBC is found in approximately $15 \%$ of newly diagnosed breast cancer patients $[2,4,5]$ and is more prevalent in younger patients ( $<50$ years) $[2,3,4,6,7]$. TNBC is associated with a more aggressive nature compared to other breast cancer subtypes, reflected by a larger tumor size, higher tumor grade, early peak of recurrence, and a worse 5-year overall survival rate $[2,5,8,9]$. To date, the only systemic treatment option for TNBC patients is chemotherapy. Multiple-targeted drugs are at various stages of development for TNBC. However, no effective-targeted therapy has been detected so far $[5,10]$.

Currently, there is a trend toward a more conservative approach of axillary staging and treatment in breast cancer. The aim is to decrease the axillary morbidity rate, while maintaining excellent regional control without affecting overall survival. Randomized controlled trials revealed that completion axillary lymph node dissection (ALND) can be safely omitted in clinically T1-2N0 breast cancer in case of limited metastatic sentinel lymph nodes (SLNs) and breast conserving treatment $[11,12]$. An ongoing trial investigates whether this is also applicable for SLN-positive patients undergoing a mastectomy (BOOG 2013-07). Further, the value of the SLN biopsy (SLNB) in current era is being questioned. Several trials randomize clinically T1(-2)N0 patients treated with breast conserving therapy to SLNB or 'watchful waiting' (BOOG 2013-08; SOUND; NCT01821768) [13].

Due to the low incidence of TNBC, only a minority of patients in these study populations represents TNBC patients, leading to insufficient power for representative results regarding this subgroup. Furthermore, clinicians are cautious on performing less axillary staging and treatment in TNBC, mainly because of its association with the aggressive nature and fewer systemic treatment options in this subtype of breast cancer patients.

It is questionable whether TNBC patients are at risk for higher regional recurrence rates and poorer overall survival when limiting or omitting axillary treatment. In the literature, studies on recurrence patterns in TNBC mainly focus on local and distant recurrence and overall survival. In order to gain more insight into recurrences in TNBC patients, and for regional recurrence in particular, we aimed to provide a nationwide overview on the occurrence of recurrence and overall survival in TNBC patients with a clinically T1-2N0 status.

\section{Methods}

\section{Study population and data collection}

All consecutive women of 18 years and older with primary invasive, clinically T1-2N0 unilateral TNBC diagnosed between 2005 and 2008, were identified from the Netherlands Cancer Registry, hosted by the Comprehensive Cancer Organisation the Netherlands (IKNL). Data are gathered by specially trained data managers in all hospitals in the Netherlands based on notification from the automated pathology archive (PALGA). Patients undergoing primary systemic treatment were not included in the selection. Patients diagnosed prior to 2005 or after 2008 were not included due to lack of registration of HER2 status, or lack of follow-up data, respectively. The following data were provided anonymized: age, performed surgical procedure(s), administration of adjuvant chemotherapy, adjuvant radiotherapy, histology of primary tumor and lymph nodes (i.e., tumor type, size, grade, and receptor status), time to event (local, regional, and distant event), vital status, and date of death or last day of followup. Five-year follow-up data on first events were available for every patient. Only first events were available, but included all events that occurred within a time frame of 3 months after diagnosis of the first event. Vital status was available up to December 31, 2014. Data were collected directly from patient records by employees of the Netherlands Cancer Registry.

\section{Axillary lymph node staging}

A clinically node negative status was defined in the 2005 Dutch breast cancer guideline as negative physical examination and axillary ultrasound [14]. Tissue sampling was recommended in case of a suspicious lymph node on axillary ultrasound. An SLNB was advised for clinically node-negative patients, followed by a completion ALND in case of a metastasis in the SLN. Isolated tumor cells were considered as pathologically node negative.

\section{Pathological technique}

The 2005 Dutch breast cancer guideline recommended to completely include SLNs of up to $0.5 \mathrm{~cm}$, to half SLNs of $0.5-1.0 \mathrm{~cm}$, and fully imbed SLNs greated than $1 \mathrm{~cm}$ in lammellas of $0.2 \mathrm{~cm}$. It was furthermore recommended to section each paraffin block at three levels with 250-micrometer intervals, but this may have varied between pathology laboratories. If no metastasis was detected with hematoxylin and eosin, immunohistochemical staining was adviced.

Lymph nodes of the (completion) ALND specimen were embedded in paraffin after formalin fixation and sliced with a recommended maximum thickness of $3 \mathrm{~mm}$, followed by hematoxylin and eosin staining.

Each lymph node was registered according to pathological findings: negative (pN0), or as isolated tumor cell ( $\mathrm{pNO}(\mathrm{i}+) ; \leq 0.2 \mathrm{~mm})$, micrometastasis $(\mathrm{pN} 1 \mathrm{mi} ; 0.2 \mathrm{~mm}$ $\leq 2.0 \mathrm{~mm}$ ), or macrometastasis $(\mathrm{pN} 1-3 ;>2.0 \mathrm{~mm})$. 
Tumors were graded according to the modified BloomRichardson grading system [15]. The ER and PR status was determined by immunohistochemistry and scored using $<10 \%$ of tumor staining as the negative cut off. The HER2 receptor status was determined by immunohistochemistry and recorded as negative in case of 0 or +1 staining, and positive in case of +3 staining. Fluorescence in situ hybridization analyses was performed in case of +2 staining.

\section{Adjuvant chemotherapy recommendations}

The 2005 Dutch breast cancer guideline recommended adjuvant chemotherapy for patients aged $<70$ years with a pathological $\mathrm{N}+$ status [14]. Furthermore, adjuvant chemotherapy was recommended in patients aged $<70$ years with a pathological N0 status in case of a tumor size $\geq 3.0 \mathrm{~cm}$, a tumor size of $2-3 \mathrm{~cm}$ and grade $2-3$, or a tumor size of $1-2 \mathrm{~cm}$ and grade 3 . For patients aged $\leq 35$ years, adjuvant chemotherapy was also considered in case of a tumor size $>1 \mathrm{~cm}$ or $\leq 1 \mathrm{~cm}$ and grade $2-3$. As regards to patients aged $\geq 70$ years, no standard advice was provided due to lack of evidence for benefit of chemotherapy in this patient group [14].

The adjuvant chemotherapy regimen mostly consisted of 5 cycles of fluorouracil-epirubicin-cyclophosphamide (FEC), or 6 cycles of docetaxel/paclitaxel-adriamycin-cyclophosphamide (TAC) [14].

\section{Adjuvant radiation therapy indications}

Breast conserving therapy consisted of breast conserving surgery followed by whole breast radiotherapy, with a fractionation scheme equivalent to $25 \times 2$ Gy, 5 fraction per week [14]. A boost could be considered in patients aged $<60$ years or in case of focal irradicality. Chest wall irradiation following mastectomy was indicated in case of irradicality, invasion of pectoralis muscle or skin, or a pathological T3-4 status. Periclavicular radiation therapy (including breast or chest wall) was indicated in case of a pathological N2-3 status or a tumorpositive axillary top, with administration of $50 \mathrm{~Gy}$ fractionated irradiation [14].

\section{Statistical analysis}

Primary endpoint of our study is regional recurrence rate within 5 years. A regional recurrence was registered by the Netherlands Cancer Registry as an event in lymph nodes of ipsilateral axilla, infraclavicular region, intramammary, or in the internal mammary lymph node chain. Secondary endpoints are local recurrence rate, distant recurrence rate, disease-free survival, distant disease-free survival, and overall survival. A local recurrence was registered as an event in the ipsilateral breast (or overlying skin) with similar morphologic characteristics as the primary tumor. Events located elsewhere in the body were registered as distant recurrence. Employees of the Netherlands Cancer Registry consulted the treating physician in case there was doubt about the occurrence of a recurrence.

Disease-free survival was defined as the time interval from date of diagnosis to a local, regional or distant recurrence, or death from any cause, whichever occurred first. Distant disease-free survival was defined as the time interval from date of diagnosis to a distant recurrence, or death from any cause, whichever occurred first. Overall survival was defined as the time interval between date of diagnosis and December 31, 2014 or date of death from any cause. Patients who were alive and disease-free were censored at the last day of follow-up (December 31, 2014).

Descriptive categorical data are presented as proportions and absolute numbers. Continuous variables are presented as means with standard deviations. Kaplan-Meier method was used to estimate the event rates at 5 years of followup. Statistical analyses were performed using Statistical Package for the Social Sciences (SPSS), version 20.0 (IBM Corporation, Armonk, NY, USA). A $p$ value of $<0.05$ was considered statistically significant.

\section{Results}

\section{Patient demographics and tumor characteristics}

A total of 2548 women with clinically T1-2N0 TNBC were identified from the Netherlands Cancer Registry. In this cohort, the mean age at diagnosis was 56 years (range $20-95$ ), with $36 \%$ of patients aged $\leq 50$ years. Patients demographics and tumor characteristics are presented in Table 1 . The majority of patients had a clinically $\mathrm{T} 1$ status $(63.5 \%)$ and a grade 3 tumor $(73.6 \%)$. Breast conserving therapy was performed in $63.7 \%$, a mastectomy in $29.9 \%$, mastectomy with adjuvant radiation therapy in $4.6 \%$, and lumpectomy-only in $1.8 \%$.

The SLNB was performed in 2486 patients $(97.6 \%)$ and 54 patients $(2.1 \%)$, primarily underwent an ALND (Fig. 1). The SLN was negative in 1875 patients (75.4\%), not found in $11(0.4 \%)$, showed isolated tumor cells in $73(2.9 \%)$, micrometastasis in 117 (4.7\%), and macrometastasis in 392 patients $(15.8 \%)$. A completion ALND was performed in 508 patients. Final pathological lymph node status of all 2548 patients was pN0 in $78.5 \%$, pN1mi in $4.5 \%$, pN1 in $12.3 \%, \mathrm{pN} 2$ in $2.5 \%$, pN3 in $1.1 \%$, and pNx in $1.1 \%$. 
Table 1 Patient demographics and tumor characteristics

\begin{tabular}{|c|c|}
\hline Characteristic & Value \\
\hline Number of Patients & 2548 \\
\hline \multicolumn{2}{|l|}{ Age } \\
\hline Mean (SD) & $56(14)$ \\
\hline Range & 20-95 \\
\hline \multicolumn{2}{|l|}{ Clinical T-stadium, $n(\%)$} \\
\hline $\mathrm{cT} 1$ & $1618(63.5)$ \\
\hline cT2 & $930(36.5)$ \\
\hline \multicolumn{2}{|l|}{ Local treatment breast, $n(\%)$} \\
\hline Breast conserving therapy & $1624(63.7)$ \\
\hline Mastectomy & 761 (29.9) \\
\hline Mastectomy and radiotherapy & $118(4.6)$ \\
\hline Lumpectomy-only & $45(1.8)$ \\
\hline \multicolumn{2}{|l|}{ Axillary surgery, $n(\%)$} \\
\hline SLNB only & $1978(77.6)$ \\
\hline ALND & $54(2.1)$ \\
\hline SLNB and completion ALND & $508(19.9)$ \\
\hline No axillary surgery & $8(0.3)$ \\
\hline \multicolumn{2}{|l|}{ Pathological T-stadium, $n(\%)$} \\
\hline pT1 & $1405(55.1)$ \\
\hline pT2 & $1095(43.0)$ \\
\hline pT3 & $34(1.3)$ \\
\hline pT4 & $3(0.1)$ \\
\hline Unknown & $11(0.4)$ \\
\hline \multicolumn{2}{|l|}{ Pathological N-stadium, $n(\%)$} \\
\hline pNO & $1929(75.7)$ \\
\hline $\mathrm{pNO}(\mathrm{i}+)$ & $72(2.8)$ \\
\hline pN1mi & $115(4.5)$ \\
\hline $\mathrm{pN} 1$ & $313(12.3)$ \\
\hline $\mathrm{pN} 2$ & $64(2.5)$ \\
\hline $\mathrm{pN} 3$ & $27(1.1)$ \\
\hline Unknown & $28(1.1)$ \\
\hline \multicolumn{2}{|l|}{ Tumor type, $n(\%)$} \\
\hline Ductal & $1275(83.4)$ \\
\hline Lobular & $47(3.1)$ \\
\hline Other & $207(13.5)$ \\
\hline \multicolumn{2}{|l|}{ Grade (Bloom-Richardson), $n(\%)$} \\
\hline Grade 1 & $106(4.2)$ \\
\hline Grade 2 & $470(18.4)$ \\
\hline Grade 3 & $1876(73.6)$ \\
\hline Unknown & $96(3.8)$ \\
\hline
\end{tabular}

$N$ number of cases, $S D$ standard deviation, $S L N B$ sentinel lymph node biopsy, $A L N D$ axillary lymph node dissection

Adjuvant chemotherapy was administered to 1534 patients $(60 \%)$. Administration of adjuvant chemotherapy per age category is presented in Table 2 . In patients aged $\leq 70$ years, $73 \%$ received adjuvant chemotherapy.

\section{Outcome}

During a follow-up of 5 years, 328 patients experienced a solitary recurrence: 25 patients $(1.0 \%)$ a regional recurrence, 60 patients $(2.4 \%)$ a local recurrence, and 243 patients $(9.5 \%)$ a distant recurrence. Concomitant disease occurred in another 75 patients: a local and regional recurrence in 10 patients $(0.4 \%)$, a local and distant recurrence in 25 patients $(1.0 \%)$, a regional and distant recurrence in 28 patients $(1.1 \%)$, and a local, regional, and distant recurrence in 12 patients $(0.5 \%)$.

Median time to the detection of any recurrence was 1.7 years (range $0.1-5.0$ years), and in $75 \%$ of the patients the recurrence was detected within 3 years after breast cancer diagnosis (interquartile range (IQR) 1.0-2.8 years). Five-year disease-free survival, and distant disease-free survival was 78.7 and $80.5 \%$, respectively. Median follow-up for overall survival was 7.7 years (IQR 6.2-8.8), with a 5-year overall survival of $82.3 \%$, and 10-year overall survival of $72.2 \%$.

\section{Regional recurrences}

A total of 75 patients $(2.9 \%)$ experienced a regional recurrence in our cohort, of whom $25(1.0 \%)$ a solitary regional recurrence, and $50(1.9 \%)$ concomitant local and/ or distant disease. Patient demographics and tumor characteristics at initial diagnosis of the 75 patients are presented in Table 3. An SLNB was performed for axillary staging after diagnosis in 74 patients, revealing no metastases in 37 patients $(50 \%)$, isolated tumor cells in two patients $(3 \%)$, micrometastasis in 5 patients $(7 \%)$, and macrometastasis in 24 patients ( $32 \%$ ). In two patients, the SLN was not found; in four patients, results were unknown; and in one patient, no SLNB was performed. A (completion) ALND was performed in 30 patients. Final pathological lymph node status was pN0 in 39 patients (52.0\%), pNOi+ in two patients $(2.7 \%)$, pN1mi in 5 patients (6.7 \%), pN1 in 19 patients $(25.3 \%), \mathrm{pN} 2$ in three patients (4.0\%), pN3 in two patients $(2.7 \%)$, and unknown in five patients. Adjuvant chemotherapy was administered to 45 patients.

The median time to the detection of the regional recurrence was 1.6 years (range 0.1-4.9). In $25 \%$ of the patients, the regional recurrence was already detected within the first year after breast cancer diagnosis, and in $75 \%$ within 2.5 years (IQR $0.8-2.5$ years).

There were 16 deaths among the 25 patients with a solitary regional recurrence and 45 deaths in case of concomitant local and/or distant recurrence, resulting in a 5-year overall survival of $28.4 \%$. The median time to death was 3.6 years (range 0.3-9.8). No additional statistical analyses were performed given the small number of events. 


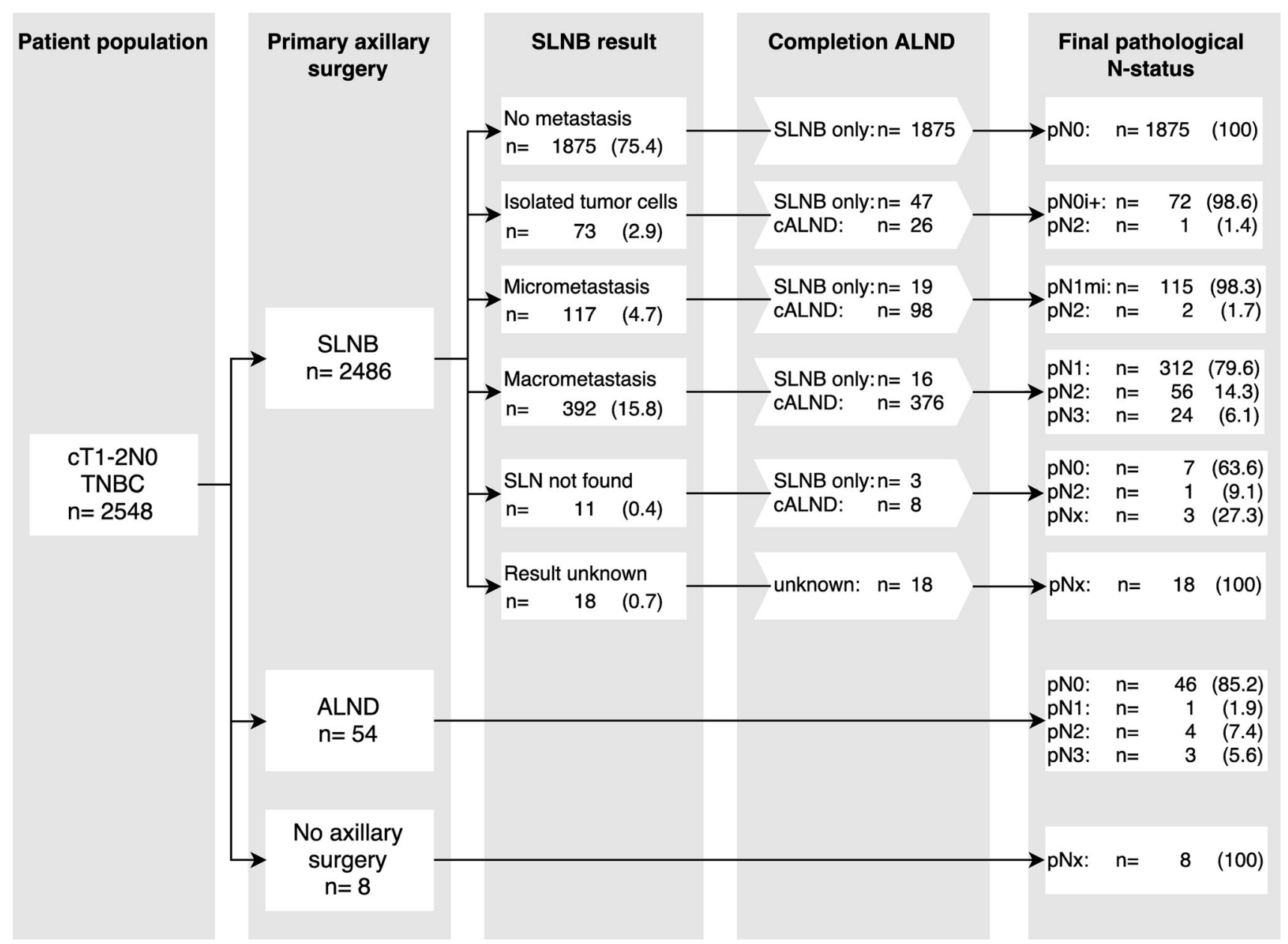

Fig. 1 Axillary lymph node staging and treatment results of the 2548 triple-negative breast cancer patients. TNBC Triple-negative breast cancer, $S L N B$ sentinel lymph node biopsy, $A L N D$ axillary lymph node dissection, $S L N$ sentinel lymph node, and $c A L N D$ completion axillary lymph node dissection

Table 2 Administered adjuvant chemotherapy per age category

\begin{tabular}{lccc}
\hline Age category & No chemotherapy & Chemotherapy & \multicolumn{1}{l}{ Total } \\
\hline 20-30 year, n (\%) & $2(3.3)$ & $58(96.7)$ & $60(2.4)$ \\
31-40 year, n (\%) & $23(7.4)$ & $286(92.6)$ & $309(12.1)$ \\
41-50 year, n (\%) & $96(17.2)$ & $462(82.8)$ & $558(21.9)$ \\
51-60 year, n (\%) & $191(29.1)$ & $465(70.9)$ & $656(25.7)$ \\
61-70 year, n (\%) & $261(50.5)$ & $256(49.5)$ & $517(20.3)$ \\
$\geq 70$ year, $n(\%)$ & $441(98.4)$ & $7(1.6)$ & $448(17.6)$ \\
Total & $1014(39.8)$ & $1534(60.2)$ & 2548 \\
\hline
\end{tabular}

\section{Discussion}

The aim of this study was to provide a nationwide overview on the occurrence of regional recurrences in patients with TNBC and a clinically T1-2N0 status, in the context of the randomized controlled trials investigating the safety of minimizing axillary staging and treatment. In this Dutch nationwide registry TNBC population, $2.9 \%$ of the patients developed a regional recurrence during 5 years of follow-up. Most were detected within 3 years after diagnosis. Distant recurrences occurred more frequently, in $12 \%$. Regional recurrences represent only a minor part of the events that occur in TNBC.

In the present cohort of $2548 \mathrm{TNBC}$ patients, all patients were staged as clinically T1-2N0. Preoperative staging included a negative axillary ultrasound, which is known to decrease the rate of extensive lymph node disease in particular [16, 17]. This resulted in a relatively favorable pathological $\mathrm{N}$-status in our cohort, with $\mathrm{pN} 0$ in $78.5 \%$, pN1mi in $4.5 \%$, pN1 in $12.3 \%$, and $\mathrm{pN} 2-3$ in $3.6 \%$. The rate of lymph node positive disease in these TNBC patients seems to correspond to other breast cancer subtypes. Regardless of the receptor status, a cohort study of 12,113 patients with clinically T1-2N0 breast cancer, who were treated with breast conserving therapy, revealed $\mathrm{pN} 0$ in $79.8 \%$, pN1mi in $7.3 \%, \mathrm{pN} 1$ in $11.1 \%$, and $\mathrm{pN} 2-3$ in $1.7 \%[17]$. 
Table 3 Characteristics of patients with a regional event diagnosed during follow-up

\begin{tabular}{|c|c|}
\hline & Regional event \\
\hline Number of events, $\%$ & $75(2.9)$ \\
\hline Median time to event in years, range & $1.6(0.1-4.9)$ \\
\hline \multicolumn{2}{|l|}{ Interquartile range time to event, years } \\
\hline $25 \%$ & 0.8 \\
\hline $75 \%$ & 2.5 \\
\hline Mean age at initial diagnosis, SD & $54(14.7)$ \\
\hline \multicolumn{2}{|l|}{ Clinical T-status, $n(\%)$} \\
\hline $\mathrm{cT} 1$ & $40(53.3)$ \\
\hline $\mathrm{cT} 2$ & $35(46.7)$ \\
\hline \multicolumn{2}{|l|}{ Local treatment breast, $n(\%)$} \\
\hline BCT & $37(49.3)$ \\
\hline Mastectomy & $31(41.3)$ \\
\hline Mastectomy + RT & $2(2.7)$ \\
\hline Lumpectomy & $5(6.7)$ \\
\hline \multicolumn{2}{|l|}{ Axillary surgery, n (\%) } \\
\hline SLNB only & $45(60.0)$ \\
\hline ALND & $1(1.3)$ \\
\hline SLNB and cALND & $29(38.7)$ \\
\hline No axillary surgery & - \\
\hline \multicolumn{2}{|l|}{ Chemotherapy, $n(\%)$} \\
\hline Yes & $45(60.0)$ \\
\hline No & $30(40.0)$ \\
\hline \multicolumn{2}{|l|}{ Pathological T-stadium, $n(\%)$} \\
\hline pT1 & $31(41.3)$ \\
\hline pT2 & $42(56.0)$ \\
\hline pT3 & $1(1.3)$ \\
\hline Unknown & $1(1.3)$ \\
\hline \multicolumn{2}{|l|}{ Pathological N-stadium, $n(\%)$} \\
\hline pNO & $39(52.0)$ \\
\hline $\mathrm{pNO}(\mathrm{i}+)$ & $2(2.7)$ \\
\hline pN1mi & $5(6.7)$ \\
\hline pN1 & $19(25.3)$ \\
\hline $\mathrm{pN} 2$ & $3(4.0)$ \\
\hline pN3 & $2(2.7)$ \\
\hline Unknown & $5(6.7)$ \\
\hline \multicolumn{2}{|l|}{ Grade, $n(\%)$} \\
\hline Grade 1 & $1(1.3)$ \\
\hline Grade 2 & $11(14.7)$ \\
\hline Grade 3 & $61(81.3)$ \\
\hline Unknown & $1(2.7)$ \\
\hline \multicolumn{2}{|l|}{ Recurrences, $n(\%)$} \\
\hline Regional & $25(33.3)$ \\
\hline Regional and local & $10(13.3)$ \\
\hline Regional and distant & $28(37.3)$ \\
\hline
\end{tabular}

Several studies investigated the association between tumor subtype and nodal status, and showed that the incidence of lymph node metastases in TNBC is equal or even
Table 3 continued

\begin{tabular}{ll}
\hline & Regional event \\
\hline Regional, local and distant & $12(16.0)$ \\
\hline
\end{tabular}

$N$ number of cases, $S D$ standard deviation, $B C T$ breast conserving therapy, $R T$ radiotherapy, $S L N B$ sentinel lymph node biopsy, $A L N D$ axillary lymph node dissection, Grade according to modified BloomRichardson

lower compared to ER-positive or HER2-positive tumors [18-22]. TNBC is associated with similar characteristics that are related to lymph node involvement, such as younger age and higher tumor grade; though, there is no association between TNBC and lymphovascular invasion $[2,8,19]$. The study of Ugras et al. revealed that all breast cancer subtypes were independently associated with lymphovascular invasion $(p<0.0001)$, with TNBC having the lowest incidence of lymphovascular invasion, which might explain a lower incidence of node positivity in some cohorts $[18,22]$.

Main focus of our study was the occurrence of regional recurrences in TNBC. Only 25 patients $(1.0 \%)$ in our cohort experienced a solitary regional recurrence and 50 patients $(1.9 \%)$ experienced regional recurrence together with a local and/or distant event. In literature, one other study reported specifically on regional recurrence in TNBC. It concerned a prospective database review questioning the safety of breast conserving therapy in TNBC. This study included 1851 patients with stage I to III breast cancer who were treated with breast conserving therapy, of whom 234 patients had TNBC. They revealed a regional recurrence rate of $1.3 \%$ at a median follow-up of 5 years in the TNBC group and $4.7 \%$ local recurrences, which were comparable to the total patient group (1.1\% regional recurrences and $2.5 \%$ local recurrences) [9]. Distant recurrence occurred in $9.0 \%$ of patients with $\mathrm{TNBC}$, compared to $3.6 \%$ for all patients together. A significant difference for distant recurrence was found between TNBC and patients with a luminal A subtype (positive for ER or PR and negative for HER2) $(p=0.001)$.

No further studies have been published on regional recurrence in TNBC, although there have been several studies on local recurrence, more specifically comparing breast conserving therapy and mastectomy. These studies showed that there is a higher rate of local recurrence in TNBC, compared to other subtypes, without significant differences for type of local breast treatment [1, 9, 23, 24, 25]. However, in one study, the increased local recurrence rate for TNBC lost significance after adjustments for factors such as age, tumor size, and grade [9]. Local recurrence rates of $4.2-10 \%$ are reported, which is slightly higher than in current study, presumably due to the fact that we included only clinically T1-2N0 patients $[1,9,24,25]$. 
The median time to any recurrence in TNBC is short compared to other subtypes, and almost all events occur within 5 years after diagnosis [26, 27]. This is also the case in our cohort, where the median time to any recurrence was 1.7 years, with even $75 \%$ of all events within 3 years after diagnosis.

The systemic treatment option for TNBC is, until now, limited to chemotherapy. In neoadjuvant chemotherapy trials, pathological complete response (PCR) rates of primary tumor and lymph nodes are reported in up to $40 \%$ in the TNBC subtype [28-32]. PCR provides prognostic information for TNBC as well as for HER2-positive (ER/ PR negative) patients. A meta-analysis of Cortazar et al. evaluated 11,955 patients from neoadjuvant chemotherapy trials and showed a PCR in $34 \%$ of TNBC patients [32]. Event-free survival and overall survival were improved in patients achieving PCR, with a hazard ratio of 0.24 (95\% CI 0.18-0.33) and 0.16 (95\% CI 0.11-0.25), respectively.

Adjuvant chemotherapy was administered to $60 \%$ of patients in our cohort. Patients treated with neoadjuvant chemotherapy were not included. The indications for adjuvant chemotherapy have been expanded over the years. Comparison of the 2005 and current 2012 Dutch breast cancer guideline shows some changes in indications $[14$, 33]. Chemotherapy is now indicated in case of a primary tumor size $>2 \mathrm{~cm}$ (vs. $\geq 3 \mathrm{~cm}$ ), and $1-2 \mathrm{~cm}$ and tumor grade $2-3$ (vs. $1-2 \mathrm{~cm}$ and tumor grade 3 ). Considering elderly, current Dutch guideline now considers chemotherapy for fit patients aged 70 years or older who are pathological lymph node positive. There further have been some changes in the regimen of adjuvant chemotherapy. Six cycles of TAC is still commonly administered in current practice, but FEC is nowadays combined with a taxane, and antracycline-based chemotherapy can be administered in combination with a taxane [33]. Preliminary research has shown that the addition of carboplatin to a taxane increases the PCR rate in TNBC, though no survival data are available yet [34]. Changements in indications and regimen of chemotherapy are likely to positively influence patients outcome.

\section{Conclusion}

Triple-negative clinically $\mathrm{T} 1-2 \mathrm{~N} 0$ breast cancer patients rarely develop a regional recurrence. Their disease-free survival is more threatened by distant recurrence, which affects their overall survival. Consequently, it seems justified to include triple-negative breast cancer patients in randomized controlled trials investigating the safety of minimizing axillary treatment.

\section{Compliance with ethical standards}

Conflict of interest The authors declare that they have no conflict of interest.

Open Access This article is distributed under the terms of the Creative Commons Attribution-NonCommercial 4.0 International License (http://creativecommons.org/licenses/by-nc/4.0/), which permits any noncommercial use, distribution, and reproduction in any medium, provided you give appropriate credit to the original author(s) and the source, provide a link to the Creative Commons license, and indicate if changes were made.

\section{References}

1. Abdulkarim BS, Cuartero J, Hanson J, Deschenes J, Lesniak D, Sabri S (2011) Increased risk of locoregional recurrence for women with T1-2N0 triple-negative breast cancer treated with modified radical mastectomy without adjuvant radiation therapy compared with breast-conserving therapy. J Clin Oncol 29(21):2852-2858. doi:10.1200/JCO.2010.33.4714

2. Dent R, Trudeau M, Pritchard KI, Hanna WM, Kahn HK, Sawka CA, Lickley LA, Rawlinson E, Sun P, Narod SA (2007) Triplenegative breast cancer: clinical features and patterns of recurrence. Clin Cancer Res 13(15 Pt 1):4429-4434. doi:10.1158/ 1078-0432.CCR-06-3045

3. Haffty BG, Yang Q, Reiss M, Kearney T, Higgins SA, Weidhaas J, Harris L, Hait W, Toppmeyer D (2006) Locoregional relapse and distant metastasis in conservatively managed triple negative early-stage breast cancer. J Clin Oncol 24(36):5652-5657. doi:10. 1200/JCO.2006.06.5664

4. Carey LA, Perou CM, Livasy CA, Dressler LG, Cowan D, Conway K, Karaca G, Troester MA, Tse CK, Edmiston S, Deming SL, Geradts J, Cheang MC, Nielsen TO, Moorman PG, Earp HS, Millikan RC (2006) Race, breast cancer subtypes, and survival in the Carolina Breast Cancer Study. JAMA 295(21):2492-2502. doi:10.1001/jama.295.21.2492

5. Newman LA, Reis-Filho JS, Morrow M, Carey LA, King TA (2015) The 2014 Society of Surgical Oncology Susan G. Komen for the Cure Symposium: triple-negative breast cancer. Ann Surg Oncol 22(3):874-882. doi:10.1245/s10434-014-4279-0

6. Bauer KR, Brown M, Cress RD, Parise CA, Caggiano V (2007) Descriptive analysis of estrogen receptor (ER)-negative, progesterone receptor (PR)-negative, and HER2-negative invasive breast cancer, the so-called triple-negative phenotype: a population-based study from the California cancer Registry. Cancer 109(9):1721-1728. doi:10.1002/cncr.22618

7. Morris GJ, Naidu S, Topham AK, Guiles F, Xu Y, McCue P, Schwartz GF, Park PK, Rosenberg AL, Brill K, Mitchell EP (2007) Differences in breast carcinoma characteristics in newly diagnosed African-American and Caucasian patients: a singleinstitution compilation compared with the National Cancer Institute's Surveillance, Epidemiology, and End Results database. Cancer 110(4):876-884. doi:10.1002/cncr.22836

8. Carey LA, Dees EC, Sawyer L, Gatti L, Moore DT, Collichio F, Ollila DW, Sartor CI, Graham ML, Perou CM (2007) The triple negative paradox: primary tumor chemosensitivity of breast cancer subtypes. Clin Cancer Res 13(8):2329-2334. doi:10.1158/ 1078-0432.CCR-06-1109

9. Gangi A, Chung A, Mirocha J, Liou DZ, Leong T, Giuliano AE (2014) Breast-conserving therapy for triple-negative breast can- 
cer. JAMA Surg 149(3):252-258. doi:10.1001/jamasurg.2013. 3037

10. Bayraktar S, Gluck S (2013) Molecularly targeted therapies for metastatic triple-negative breast cancer. Breast Cancer Res Treat 138(1):21-35. doi:10.1007/s10549-013-2421-5

11. Galimberti V, Cole BF, Zurrida S, Viale G, Luini A, Veronesi P, Baratella P, Chifu C, Sargenti M, Intra M, Gentilini O, Mastropasqua MG, Mazzarol G, Massarut S, Garbay JR, Zgajnar J, Galatius H, Recalcati A, Littlejohn D, Bamert M, Colleoni M, Price KN, Regan MM, Goldhirsch A, Coates AS, Gelber RD, Veronesi U, International Breast Cancer Study Group Trial i (2013) Axillary dissection versus no axillary dissection in patients with sentinel-node micrometastases (IBCSG 23-01): a phase 3 randomised controlled trial. Lancet Oncol 14(4): 297-305. doi: 10.1016/S1470-2045(13)70035-4

12. Giuliano AE, Hunt KK, Ballman KV, Beitsch PD, Whitworth PW, Blumencranz PW, Leitch AM, Saha S, McCall LM, Morrow M (2011) Axillary dissection vs no axillary dissection in women with invasive breast cancer and sentinel node metastasis: a randomized clinical trial. JAMA 305(6):569-575. doi:10.1001/jama.2011.90

13. Gentilini O, Veronesi U (2012) Abandoning sentinel lymph node biopsy in early breast cancer? A new trial in progress at the European Institute of Oncology of Milan (SOUND: Sentinel node vs Observation after axillary UltraSouND). Breast 21(5):678681. doi:10.1016/j.breast.2012.06.013

14. NABON (2005) Guideline mammacarcinoma 2005. The Netherlands

15. Elston CW, Ellis IO (1991) Pathological prognostic factors in breast cancer. I. The value of histological grade in breast cancer: experience from a large study with long-term follow-up. Histopathology 19(5):403-410

16. Schipper RJ, van Roozendaal LM, de Vries B, Pijnappel RM, Beets-Tan RG, Lobbes MB, Smidt ML (2013) Axillary ultrasound for preoperative nodal staging in breast cancer patients: is it of added value? Breast 22(6):1108-1113. doi:10.1016/j.breast. 2013.09.002

17. Duijsens GHNM, van Roozendaal LM, Schipper RJ, Paiman EHM, Siesling S, Pijnappel RM, Lobbes MBI, Smidt ML (2014) Minor risk of extensive lymph node metastases after a negative axillary ultrasound in breast cancer patients in the Netherlands. Dutch J Oncol 11:268-273

18. Crabb SJ, Cheang MC, Leung S, Immonen T, Nielsen TO, Huntsman DD, Bajdik CD, Chia SK (2008) Basal breast cancer molecular subtype predicts for lower incidence of axillary lymph node metastases in primary breast cancer. Clin Breast Cancer 8(3):249-256. doi:10.3816/CBC.2008.n.028

19. Gangi A, Mirocha J, Leong T, Giuliano AE (2014) Triple-negative breast cancer is not associated with increased likelihood of nodal metastases. Ann Surg Oncol 21(13):4098-4103. doi:10. 1245/s10434-014-3989-7

20. Reyal F, Rouzier R, Depont-Hazelzet B, Bollet MA, Pierga JY, Alran S, Salmon RJ, Fourchotte V, Vincent-Salomon A, SastreGarau X, Antoine M, Uzan S, Sigal-Zafrani B, De Rycke Y (2011) The molecular subtype classification is a determinant of sentinel node positivity in early breast carcinoma. PLoS One 6(5):e20297. doi:10.1371/journal.pone.0020297

21. Wiechmann L, Sampson M, Stempel M, Jacks LM, Patil SM, King T, Morrow M (2009) Presenting features of breast cancer differ by molecular subtype. Ann Surg Oncol 16(10):2705-2710. doi:10.1245/s10434-009-0606-2

22. Ugras S, Stempel M, Patil S, Morrow M (2014) Estrogen receptor, progesterone receptor, and HER2 status predict lymphovascular invasion and lymph node involvement. Ann Surg Oncol 21(12):3780-3786. doi:10.1245/s10434-014-3851-y

23. Adkins FC, Gonzalez-Angulo AM, Lei X, Hernandez-Aya LF, Mittendorf EA, Litton JK, Wagner J, Hunt KK, Woodward WA, Meric-Bernstam F (2011) Triple-negative breast cancer is not a contraindication for breast conservation. Ann Surg Oncol 18(11):3164-3173. doi:10.1245/s10434-011-1920-z

24. Lowery AJ, Kell MR, Glynn RW, Kerin MJ, Sweeney KJ (2012) Locoregional recurrence after breast cancer surgery: a systematic review by receptor phenotype. Breast Cancer Res Treat 133(3):831-841. doi:10.1007/s10549-011-1891-6

25. Zumsteg ZS, Morrow M, Arnold B, Zheng J, Zhang Z, Robson M, Traina T, McCormick B, Powell S, Ho AY (2013) Breast-conserving therapy achieves locoregional outcomes comparable to mastectomy in women with T1-2N0 triple-negative breast cancer. Ann Surg Oncol 20(11):3469-3476. doi:10.1245/s10434-013-3011-9

26. Boyle P (2012) Triple-negative breast cancer: epidemiological considerations and recommendations. Ann Oncol 23(Suppl 6):vi7-12. doi:10.1093/annonc/mds187

27. Millar EK, Graham PH, O'Toole SA, McNeil CM, Browne L, Morey AL, Eggleton S, Beretov J, Theocharous C, Capp A, Nasser E, Kearsley JH, Delaney G, Papadatos G, Fox C, Sutherland RL (2009) Prediction of local recurrence, distant metastases, and death after breast-conserving therapy in earlystage invasive breast cancer using a five-biomarker panel. J Clin Oncol 27(28):4701-4708. doi:10.1200/JCO.2008.21.7075

28. Carey LA, Metzger R, Dees EC, Collichio F, Sartor CI, Ollila DW, Klauber-DeMore N, Halle J, Sawyer L, Moore DT, Graham ML (2005) American Joint Committee on Cancer tumor-nodemetastasis stage after neoadjuvant chemotherapy and breast cancer outcome. J Natl Cancer Inst 97(15):1137-1142. doi:10. 1093/jnci/dji206

29. Fisher B, Bryant J, Wolmark N, Mamounas E, Brown A, Fisher ER, Wickerham DL, Begovic M, DeCillis A, Robidoux A, Margolese RG, Cruz AB Jr, Hoehn JL, Lees AW, Dimitrov NV, Bear HD (1998) Effect of preoperative chemotherapy on the outcome of women with operable breast cancer. J Clin Oncol 16(8):2672-2685

30. Hennessy BT, Hortobagyi GN, Rouzier R, Kuerer H, Sneige N, Buzdar AU, Kau SW, Fornage B, Sahin A, Broglio K, Singletary SE, Valero V (2005) Outcome after pathologic complete eradication of cytologically proven breast cancer axillary node metastases following primary chemotherapy. J Clin Oncol 23(36):9304-9311. doi:10.1200/JCO.2005.02.5023

31. Symmans WF, Peintinger F, Hatzis C, Rajan R, Kuerer H, Valero V, Assad L, Poniecka A, Hennessy B, Green M, Buzdar AU, Singletary SE, Hortobagyi GN, Pusztai L (2007) Measurement of residual breast cancer burden to predict survival after neoadjuvant chemotherapy. J Clin Oncol 25(28):4414-4422. doi:10. 1200/JCO.2007.10.6823

32. Cortazar P, Zhang L, Untch M, Mehta K, Costantino JP, Wolmark N, Bonnefoi H, Cameron D, Gianni L, Valagussa P, Swain SM, Prowell T, Loibl S, Wickerham DL, Bogaerts J, Baselga J, Perou C, Blumenthal G, Blohmer J, Mamounas EP, Bergh J, Semiglazov V, Justice R, Eidtmann H, Paik S, Piccart M, Sridhara R, Fasching PA, Slaets L, Tang S, Gerber B, Geyer CE Jr, Pazdur R, Ditsch N, Rastogi P, Eiermann W, von Minckwitz G (2014) Pathological complete response and long-term clinical benefit in breast cancer: the CTNeoBC pooled analysis. Lancet 384(9938):164-172. doi:10.1016/S0140-6736(13)62422-8

33. NABON (2012) Guideline mammacarcinoma 2012. The Netherlands. http://www.oncoline.nl/uploaded/docs/mammacarci noom/Dutch\%20Breast\%20Cancer\%20Guideline\%202012.pdf

34. Sikov WM, Berry DA, Perou CM, Singh B, Cirrincione CT, Tolaney SM, Kuzma CS, Pluard TJ, Somlo G, Port ER, Golshan M, Bellon JR, Collyar D, Hahn OM, Carey LA, Hudis CA, Winer EP (2015) Impact of the addition of carboplatin and/or bevacizumab to neoadjuvant once-per-week paclitaxel followed by dose-dense doxorubicin and cyclophosphamide on pathologic complete response rates in stage II to III triple-negative breast cancer: CALGB 40603 (Alliance). J Clin Oncol 33(1):13-21. doi:10.1200/JCO.2014.57.0572 